\title{
Glass crystallization making red phosphor for high-power warm white lighting
}

\author{
Tao Hu', Lixin Ning², Yan Gao ${ }^{3}$, Jianwei Qiao', Enhai Song ${ }^{1}$, Zitao Chen (1)', Yayun Zhou', Jing Wang $\mathbb{D}^{4}$, \\ Maxim S. Molokeev ${ }^{5,6,7}$, Xiaoxing $\mathrm{Ke}^{8}$, Zhiguo Xia ${ }^{1}$ and Qinyuan Zhang ${ }^{1}$
}

\begin{abstract}
Rapid development of solid-state lighting technology requires new materials with highly efficient and stable luminescence, and especially relies on blue light pumped red phosphors for improved light quality. Herein, we discovered an unprecedented red-emitting $\mathrm{Mg}_{2} \mathrm{Al}_{4} \mathrm{Si}_{5} \mathrm{O}_{18}: \mathrm{Eu}^{2+}$ composite phosphor $\left(\lambda_{\text {ex }}=450 \mathrm{~nm}, \lambda_{\text {em }}=620 \mathrm{~nm}\right)$ via the crystallization of $\mathrm{MgO}-\mathrm{Al}_{2} \mathrm{O}_{3}-\mathrm{SiO}_{2}$ aluminosilicate glass. Combined experimental measurement and first-principles calculations verify that $\mathrm{Eu}^{2+}$ dopants insert at the vacant channel of $\mathrm{Mg}_{2} \mathrm{Al}_{4} \mathrm{Si}_{5} \mathrm{O}_{18}$ crystal with six-fold coordination responsible for the peculiar red emission. Importantly, the resulting phosphor exhibits high internal/external quantum efficiency of $94.5 / 70.6 \%$, and stable emission against thermal quenching, which reaches industry production. The maximum luminous flux and luminous efficiency of the constructed laser driven red emitting device reaches as high as $274 \mathrm{Im}$ and $54 \mathrm{Im} \mathrm{W}^{-1}$, respectively. The combinations of extraordinary optical properties coupled with economically favorable and innovative preparation method indicate, that the $\mathrm{Mg}_{2} \mathrm{Al}_{4} \mathrm{Si}_{5} \mathrm{O}_{18}: \mathrm{Eu}^{2+}$ composite phosphor will provide a significant step towards the development of high-power solid-state lighting.
\end{abstract}

\section{Introduction}

Solid-state lighting (SSL) has advanced rapidly over the past decades, and will definitely dominate the future lighting market ${ }^{1-3}$. The current standard architecture for SSL is the phosphor-converted light-emitting diode (pcLED), where the blue LED chip is covered with one or more down-shifting phosphors dispersed in organic binder to produce composite white light ${ }^{4-7}$. Despite those spectacular success in the pc-LED, the notorious "efficiency drop", that is nonthermal drop in efficiency with increasing input power density, ${ }^{8,9}$ precludes pc-LED operation in the fields, where high luminance and

Correspondence: Lixin Ning (ninglx@mail.ahnu.edu.cn) or

Zhiguo Xia (xiazg@scut.edu.cn) or Qinyuan Zhang (qyzhang@scut.edu.cn)

${ }^{1}$ School of Physics and Optoelectronics, State Key Laboratory of Luminescent

Materials and Devices and Guangdong Provincial Key Laboratory of Fiber Laser Materials and Applied Techniques, South China University of Technology,

Guangzhou, Guangdong, China

${ }^{2}$ Anhui Key Laboratory of Optoelectric Materials Science and Technology, Key Laboratory of Functional Molecular Solids, Ministry of Education, Anhui Normal University, Wuhu, Anhui, China

Full list of author information is available at the end of the article luminous fluxes lighting source are required. Recently, laser diode (LD) driven SSL approach, whereby a focused laser beam illuminates a phosphor color converter, can generate luminance far exceeding the state-of-art LED source by factors of $2-10^{10}$. This way is particularly attractive for automotive headlamp, outdoor lighting, multimedia projectors, laser TVs and so ${ }^{11}{ }^{11}$. However, the thermal shock of laser is extreme, making the traditional organic binders with poor physical and chemical stability undesired for LD applications ${ }^{12}$. Accordingly, extensive efforts are preoccupied in the exploitation of new materials with highly efficient and stable luminescence, including single crystal phosphor, polycrystalline ceramic phosphor, and phosphor-in-glass $(\mathrm{PiG})^{11,13-16}$.

Although various types of bulk phosphors have been designed and constructed successfully so far, actually almost all reports are limited to $\mathrm{Ce}^{3+}$-doped garnet-type yellow-emitting $\mathrm{PiG} /$ ceramic composite phosphors $^{17,18}$. Apparently, the high-power white lighting device based on "blue laser + yellow-emitting YAG:Ce ${ }^{3+}$ garnet" scheme is still flawed in application for the lack of red

\section{(c) The Author(s) 2021}

\footnotetext{
(c) Open Access This article is licensed under a Creative Commons Attribution 4.0 International License, which permits use, sharing, adaptation, distribution and reproduction in any medium or format, as long as you give appropriate credit to the original author(s) and the source, provide a link to the Creative Commons license, and indicate if changes were made. The images or other third party material in this article are included in the article's Creative Commons license, unless indicated otherwise in a credit line to the material. If material is not included in the article's Creative Commons license and your intended use is not permitted by statutory regulation or exceeds the permitted use, you will need to obtain permission directly from the copyright holder. To view a copy of this license, visit http://creativecommons.org/licenses/by/4.0/.
} 
component, resulting a pale white light with high correlated color temperature (CCT $>7500 \mathrm{~K}$ ) and low color rendering index $(C R I<75)^{19,20}$. Thus, the discovery of efficient red-emitting bulk phosphor is essential. Concerning this case, particular efforts have been made to fabricate red-emitting $\mathrm{CaAlSiN}_{3}: \mathrm{Eu}^{2+} \mathrm{PiG} /$ ceramic composite $^{21,22}$, but few of them can fulfill the high demands generated by practice applications. The reasons are (1) $\mathrm{CaAlSiN}_{3}: \mathrm{Eu}^{2+}$ phosphor unavoidably suffers from erosion when co-sintering it with glass frit at hightemperature $^{17}$, which leads an inferior luminescent performance, viz., a lower quantum efficiency and stronger thermal emission quenching compared with the fresh $\mathrm{CaAlSiN}_{3}: \mathrm{Eu}^{2+}$ phosphor powder. (2) The construction of ceramic is strictly constrained by high-pressure and highvacuum conditions ${ }^{15,18,22}$, and then such complex and economically unfavorable preparation processes hinder it from industrial production.

Crystallization of inorganic glass helps to realize new crystal formation and transformation for bulk composites with new functionalities in a pressureless, cost-effective, and scalable way in one step ${ }^{23-25}$, as a typical example found in the in situ crystallization of a yellow-emitting $\mathrm{Y}_{3} \mathrm{Al}_{5} \mathrm{O}_{12}: \mathrm{Ce}^{3+}$ nano-phosphor from $\mathrm{Y}_{2} \mathrm{O}_{3}-\mathrm{Al}_{2} \mathrm{O}_{3}$ glass ${ }^{25}$. Despite that, formidable challenges still remained for this strategy to develop red-emitting $\mathrm{Eu}^{2+}$ activate bulk phosphor, and actually there is no report concerning this to the best of our knowledge. The major challenge mainly stems from the fact that one can hardly crystallize a host with suitable magnitude of centroid shift/crystal field splitting energy for the dopant, which can set the energy of $5 d$ levels right at red electromagnetic spectrum region. Even so, encouraged by the large degree of freedom in glass composition design and the highly controllable crystallization processes, and thereby it enables us to intentionally manipulate spectroscopic features ${ }^{26,27}$, breathtaking innovations of preparing red-emitting composite phosphor can be achieved prospectively.

Herein, a glass crystallization engineering route for redemitting phosphor is experimentally demonstrated for the first time. Specifically, by carefully designing the aluminosilicate glass matrix and conducting crystallization, we realize the fabrication of red-emitting $\mathrm{Mg}_{2} \mathrm{Al}_{4} \mathrm{Si}_{5} \mathrm{O}_{18}$ : $\mathrm{Eu}^{2+}$ cordierite phosphor with near-unity photoluminescence quantum efficiency and excellent thermal stability. Noteworthy, cordierite $\left(\mathrm{Mg}_{2} \mathrm{Al}_{4} \mathrm{Si}_{5} \mathrm{O}_{18}\right)$ is a famous material for its technologically important applications in integrated circuit substrates, electronic packaging, automotive catalyst, thermal insulation, and kiln furniture ${ }^{28}$. It is also an excellent candidate for luminescent host accommodating various activators, particularly, by doping $\mathrm{Eu}^{2+}$ into $\mathrm{Mg}_{2} \mathrm{Al}_{4} \mathrm{Si}_{5} \mathrm{O}_{18}$. Several studies showed $\mathrm{Mg}_{2} \mathrm{Al}_{4} \mathrm{Si}_{5} \mathrm{O}_{18}: \mathrm{Eu}^{2+}$ exhibited single-band blue emission $^{29-31}$, and recently dual-band emission with strong blue and weak red luminescence was also reported ${ }^{32}$. However, it is a challenge to address the $\mathrm{Eu}^{2+}$ luminescence and its crystallographic occupancy, and more importantly, one cannot prepare the important redemitting phosphors pumped by blue light in this system. Herein, novel red $\mathrm{Mg}_{2} \mathrm{Al}_{4} \mathrm{Si}_{5} \mathrm{O}_{18}: \mathrm{Eu}^{2+}$ bulk composite has been reported, and combined experimental and theoretical investigations are performed to uncover the relationships between crystallographic structures and luminescence properties. Moreover, the laser driven redemitting device constructed using $\mathrm{Mg}_{2} \mathrm{Al}_{4} \mathrm{Si}_{5} \mathrm{O}_{18}: \mathrm{Eu}^{2+}$ exhibits a high luminous flux and luminous efficiency, demonstrating it can serve as efficient color converter for high-power warm white-lighting application. Indeed, a high-quality warm white-lighting with a low CCT $(4146 \mathrm{~K})$ and excellent CRI $\left(R_{\mathrm{a}}=85.2, R_{9}=64.5\right)$ is also fulfilled.

\section{Results and discussion \\ Fabrication of red-emitting $\mathrm{Mg}_{2} \mathrm{Al}_{4} \mathrm{Si}_{5} \mathrm{O}_{18}: \mathrm{Eu}^{2+}$ composite via glass crystallization}

Glass is a thermodynamically metastable (non-equilibrium) solid. After it is heat-treated for a sufficiently long time at higher than glass transition temperature $T_{\mathrm{g}}$, it will enter into super-cooled state, and then glass structure relaxation could occur, leading to the movement/diffusion of multiple structural building blocks simultaneously or atomic rearrangements orderly. Consequently, precipitating thermodynamically stable (equilibrium) crystal occurred with reducing the free energy of the system, as schematically depicted in Fig. 1a and inset $1 a^{33}$. Theoretically, by carefully selecting glass system and designing chemical compositions (i.e., by controlling over the topological structure of glass network, especially the medium-, or short-range structural arrangement), one may intentionally manipulate nucleation/growth of crystalline within glass as desired. As demonstrated by the typical example of $\mathrm{MgO}-\mathrm{Al}_{2} \mathrm{O}_{3}-\mathrm{SiO}_{2}$ ternary phase diagram $^{34}$ (Fig. 1b), the tailoring of those ternary compositions could selectively crystallize several types of crystallines of spinel, mullite, forsterite, and cordierite, which are all well-known hosts to accommodate opticalactive impurities. Herein, aluminosilicate precursor glass (PG) with the nominal chemical composition of $2 \mathrm{MgO}$ $\mathrm{Al}_{2} \mathrm{O}_{3}-3 \mathrm{SiO}_{2}$, which is at the boundary between cordierite (chemical formula of $\mathrm{Mg}_{2} \mathrm{Al}_{4} \mathrm{Si}_{5} \mathrm{O}_{18}$ ) and spinel (Fig. 1b), was specially designed and prepared via meltquenching method. Broad XRD scattering at about $2 \theta=$ $25^{\circ}$ together without any diffraction peaks confirm the amorphous structure of network of the as-quenched PG. EDS examination shows the homogeneously distribution of elements and its chemical compositions (Fig. S1), with the atom ratio of $\mathrm{Mg} / \mathrm{Al} / \mathrm{Si}$ in accordance with the nominal compositions (Table S1). The thermodynamic 

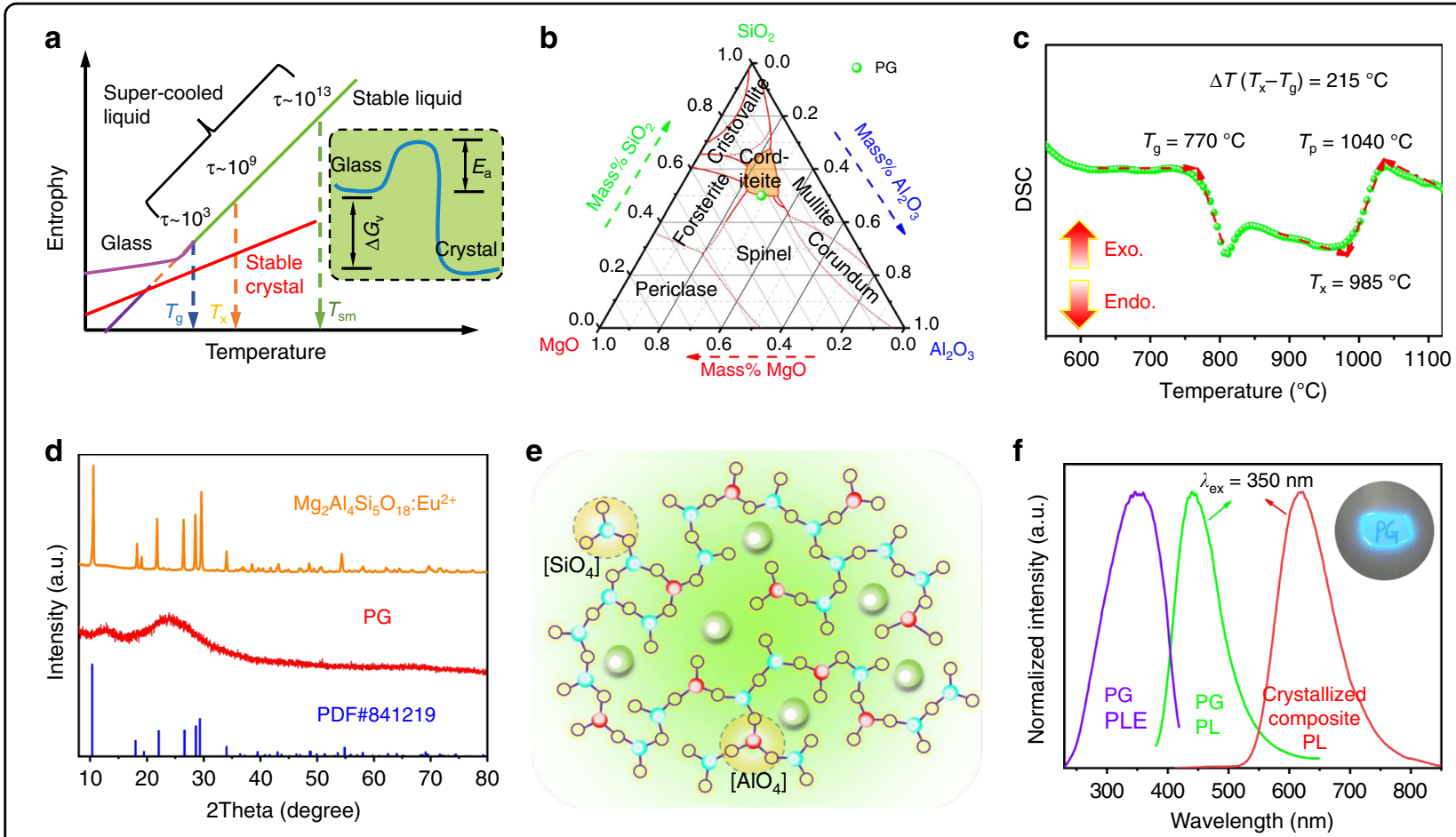

Fig. 1 Design and fabrication of $\mathrm{Mg}_{2} \mathrm{Al}_{4} \mathrm{Si}_{5} \mathrm{O}_{18}: \mathrm{Eu}^{2+}$ composite phosphor. a Schematic illustration for the entropy of glass, stable crystal, supercooled liquid, and stable liquid as a function of temperature. $T_{\mathrm{g}}, T_{\mathrm{x}}$ and $T_{\mathrm{sm}}$ are the glass transition temperature, crystallization onset temperature, and the melting temperature of stable crystal, respectively. The inset illustrates free energy evolution of the system as glass crystallization proceeds. $\Delta G_{v}$ means Gibbs free energy difference between metastable glass and stable crystal, and $E_{a}$ represents activated energy that needs to be overcome upon glass crystallization. $\mathbf{b} \mathrm{MgO}-\mathrm{Al}_{2} \mathrm{O}_{3}-\mathrm{SiO}_{2}$ phase diagram, showing the $\mathrm{PG}$ composition in wt\%. $\mathbf{c}$ DSC curve of PG recorded at a heating rate of $10 \mathrm{~K} /$ min. $\mathbf{d}$ XRD patterns of $\mathrm{PG}$ and the crystallized composite. e Schematic illustration of the two-dimensional structure of amorphous aluminosilicate glass network. $\mathbf{f} \mathrm{PL}$ spectra of $\mathrm{PG}$ and the crystallized $\mathrm{Mg}_{2} \mathrm{Al}_{4} \mathrm{Si}_{5} \mathrm{O}_{18}: \mathrm{Eu}^{2+}$ composite under $350 \mathrm{~nm}$ UV excitation, and PLE of PG measured by monitoring $450 \mathrm{~nm}$ emission, the inset photograph shows the PG taken under UV light irradiation

parameters of the PG were recorded by DSC thermogram (Fig. 1c), where the glass transition temperature $T_{\mathrm{g}}$, the onset of crystallization temperature $T_{\mathrm{x}}$, and maximum crystallization temperature $T_{\mathrm{p}}$ are determined to be 770 , 985 , and $1040{ }^{\circ} \mathrm{C}$, respectively. The temperature difference $\Delta T\left(T_{\mathrm{x}}-T_{\mathrm{g}}\right)$ is calculated to be $215{ }^{\circ} \mathrm{C}$, and such a big value is due to the fact that the glass network structure constructed by $\mathrm{Al}_{2} \mathrm{O}_{3}$ and $\mathrm{SiO}_{2}$ is rigid and thermally stable. Specifically, the glass structure relaxation and crystallization were processed via a heat-treatment at $1120^{\circ} \mathrm{C}$, which is slightly higher than $T_{\mathrm{p}}$. As shown in Fig. $1 \mathrm{~d}$, after annealing, the glass hump disappeared completely and the sharp diffraction peaks are indexed to $\mathrm{Mg}_{2} \mathrm{Al}_{4} \mathrm{Si}_{5} \mathrm{O}_{18}$ (PDF\#841219) phase, manifesting the high crystallinity and the successful preparation of $\mathrm{Mg}_{2} \mathrm{Al}_{4}$ $\mathrm{Si}_{5} \mathrm{O}_{18}$ bulk composite. The precipitation of $\mathrm{Mg}_{2} \mathrm{Al}_{4} \mathrm{Si}_{5} \mathrm{O}_{18}$ crystal matches well with $\mathrm{MgO}-\mathrm{Al}_{2} \mathrm{O}_{3}-\mathrm{SiO}_{2}$ ternary phase diagram predication (Fig. 1b). $\mathrm{Mg}_{2} \mathrm{Al}_{4} \mathrm{Si}_{5} \mathrm{O}_{18}$ is known to crystallize in two polymorphs, hightemperature hexagonal structure and low-temperature orthorhombic. To clarify the structure and the phase purity, Rietveld refinement was conducted with the high- quality synchrotron XRD data by using TOPAS $4.2^{35}$, as shown in Fig. S2. Almost all peaks were indexed by hexagonal cell $(P 6 / m c c)$ with parameters close to $\mathrm{Mg}_{2} \mathrm{Al}_{4}$ $\mathrm{Si}_{5} \mathrm{O}_{18}$, except for several weak diffraction peaks of forsterite impurity phase. The amount of $\mathrm{Mg}_{2} \mathrm{Al}_{4} \mathrm{Si}_{5} \mathrm{O}_{18}$ : $\mathrm{Eu}^{2+}$ phase, determined by Rietveld refinement, is $95.8 \%$ by weight. Refinement taking hexagonal structure as starting model was stable and gave low $R$-factors (Table S2). Coordinates of atoms and main bond lengths are listed in Tables S3 and S4, respectively.

Due to the sensitivity of Fourier-transform infrared (FTIR) spectra to short-range interactions, the FTIR spectra were measured, aiming to gain knowledge of the network topology evolution from glass to hexagonal $\mathrm{Mg}_{2} \mathrm{Al}_{4} \mathrm{Si}_{5} \mathrm{O}_{18}$ crystal. As shown in Fig. S3, the PG exhibits three absorption bands in the region of $400-1400 \mathrm{~cm}^{-1}$. The intense bands in $800-1200 \mathrm{~cm}^{-1}$ are assigned to the stretching vibrations of the $\left[\mathrm{SiO}_{4}\right]$ tetrahedron with a different number of bridging oxygen atoms $\left(1150 \mathrm{~cm}^{-1}\right.$ for $\mathrm{Q}^{4}, 1090 \mathrm{~cm}^{-1}$ for $\mathrm{Q}^{3}$, and $980 \mathrm{~cm}^{-1}$ for $\mathrm{Si}-\mathrm{O}-\left[\mathrm{NBO}\right.$, non-bridging oxygen] $\left(\mathrm{Q}^{3}\right)$ per $\left[\mathrm{SiO}_{4}\right]$ tetrahedron). The next intense band between 


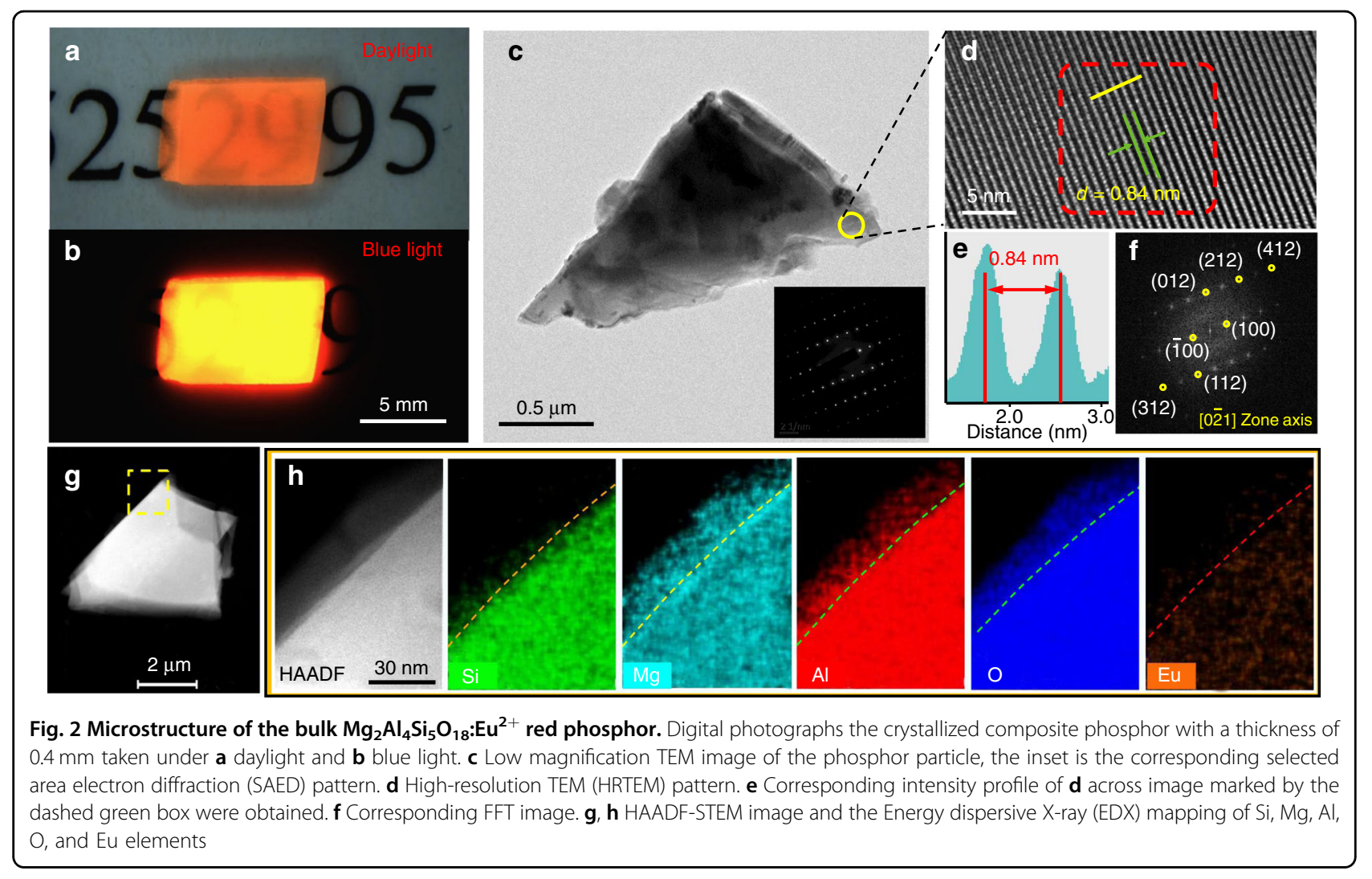

400 and $600 \mathrm{~cm}^{-1}$ are due to bending vibrations of $\mathrm{Si}-\mathrm{O}-\mathrm{Si}$ and $\mathrm{Si}-\mathrm{O}-\mathrm{Al}$ linkages, and the band in the $600-800 \mathrm{~cm}^{-1}$ region relates to the stretching vibrations of the $\mathrm{Al}-\mathrm{O}$ bonds with aluminum ions in fourfold coordination ${ }^{36}$. All those indicate that the glass network essentially consists of $\left[\mathrm{AlO}_{4}\right]$ and $\left[\mathrm{SiO}_{4}\right]$ tetrahedrons (Fig. 1e). The small $\mathrm{Mg}^{2+}$ cation acts as network modifier to balance the negative charges of either non-bridging oxygen ions or tetrahedral structure unites. The glass crystallization results in the characteristic modification of FTIR with its profile approximately coinciding with that of the PG, implying that the structure of the PG and crystal in the shortrange scale are topologically identical. As a result of the ordered reconstruction of $\left[\mathrm{AlO}_{4}\right]$ and $\left[\mathrm{SiO}_{4}\right]$ tetrahedrons, the absorption peak for the composite becomes split and rather sharp, and the quite intense band at $\sim 575 \mathrm{~cm}^{-1}$ is the typical vibration of the 6 membered aluminosilicate rings in $\mathrm{Mg}_{2} \mathrm{Al}_{4} \mathrm{Si}_{5} \mathrm{O}_{18}$ $\mathrm{crystal}^{37}$. It is believed that heterogeneity structure on the nanometer scale of the PG plays a decisive role in precipitating $\mathrm{Mg}_{2} \mathrm{Al}_{4} \mathrm{Si}_{5} \mathrm{O}_{18}$ crystal. The structure and chemical composition of nano-scale heterogeneity part might be closely related to the initial crystalline phase (topological crystalline-like ordering exists) ${ }^{33}$, which favors precipitating $\mathrm{Mg}_{2} \mathrm{Al}_{4} \mathrm{Si}_{5} \mathrm{O}_{18}$ when heat energies are being supplied.
In addition to phase transformation engineering, chemical surrounding for the optical-active dopant was tailored simultaneously, resulting in intriguing optical properties. As exhibited in Fig. If and inset of Fig. 1f, upon introducing $\mathrm{Eu}^{2+}$ dopant into the as-made PG, it exhibits bright blue light at $\sim 450 \mathrm{~nm}$. Interestingly, blue emission is almost vanished and red emission is dominated for the final crystallized composite, suggesting the glass relaxation and crystallization energetically drives the $\mathrm{Eu}^{2+}$ dopants from aluminosilicate glass towards the precipitated $\mathrm{Mg}_{2} \mathrm{Al}_{4} \mathrm{Si}_{5} \mathrm{O}_{18}$ crystalline lattice with a more prominent crystal filed splitting, and the completely vanishment of blue emission also indicates the high doping efficiency.

\section{Microstructure analysis}

Figure $2 \mathrm{a}, \mathrm{b}$ exhibit the photographs of the bulk $\mathrm{Mg}_{2} \mathrm{Al}_{4} \mathrm{Si}_{5} \mathrm{O}_{18}: \mathrm{Eu}^{2+}$ composite phosphor taking under daylight and $450 \mathrm{~nm}$ blue light excitation. The apparent body color is orange red vividly, and bright red luminescence is observed upon blue light irradiation (Fig. 2a). It is also at a high level of densification and no pores or voids could be observed at various magnification scales (Fig. S4). TEM image and the corresponding SAED pattern (Fig. 2c and inset of Fig. 2c) demonstrate the single crystalline feature with high crystallinity of microparticle. The high-resolution TEM (HRTEM) pattern shows the 

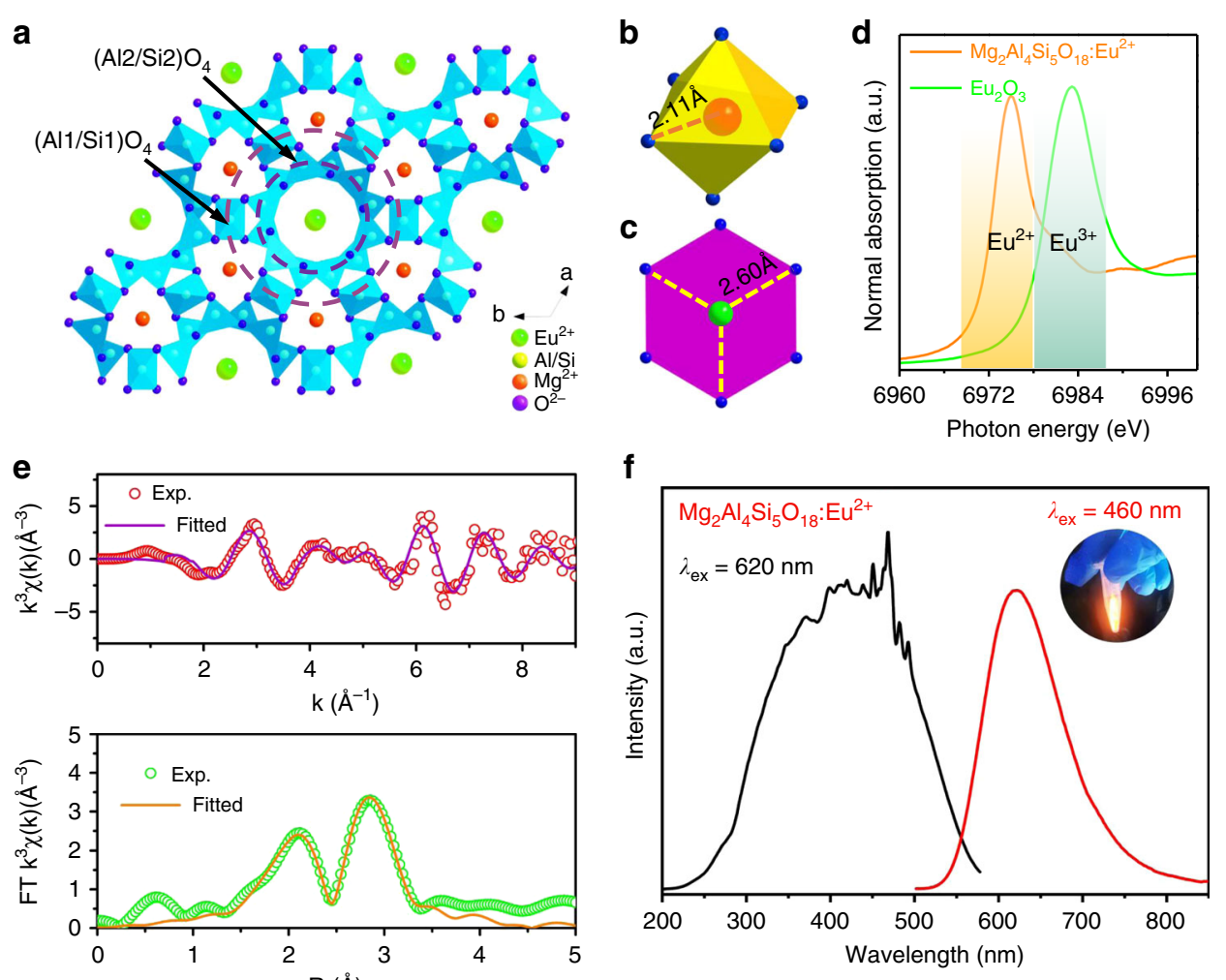

Fig. 3 Crystal structure, local structure analysis and optical properties of the $\mathrm{Mg}_{2} \mathrm{Al}_{4} \mathrm{Si}_{5} \mathrm{O}_{18}: \mathrm{Eu}^{2+}$ composite phosphor. a $2 \times 2 \times 2$ type supercell of hexagonal $\mathrm{Mg}_{2} \mathrm{Al}_{4} \mathrm{Si}_{5} \mathrm{O}_{18}: \mathrm{Eu}^{2+}$ crystal structure viewing along c-axis. The local coordination of $\mathbf{b} \mathrm{MgO}_{6}$ and $\mathbf{c}$ EuO 6 polyhedron, showing the $\mathrm{Mg}-\mathrm{O}$ and Eu-O bond lengths. $\mathbf{d}$ X-ray absorption near-edge structure (XANES) spectra of the Eu $L_{3}$ edge in $\mathrm{Mg}_{2} \mathrm{Al}_{4} \mathrm{Si}_{5} \mathrm{O}_{18}$ : $\mathrm{Eu}^{2+}$ and $\mathrm{Eu}_{2} \mathrm{O}_{3}$. e $k^{3}-$ weighted Eu $L_{3}$ edge EXAFS spectra and the corresponding Fourier transform of the $\mathrm{Mg}_{2} \mathrm{Al}_{4} \mathrm{Si}_{5} \mathrm{O}_{18}: \mathrm{Eu}^{2+}$ composite fitting as a function of R. $\mathbf{f}$ Room temperature PLE and PL spectra of $\mathrm{Mg}_{2} \mathrm{Al}_{4} \mathrm{Si}_{5} \mathrm{O}_{18}: \mathrm{Eu}^{2+}$ composite, the sharp lines around $450 \mathrm{~nm}$ in PLE spectra are caused by xenon lamp light scattering and the spectra is uncorrected. The inset shows the powder under $365 \mathrm{~nm}$ light UV irradiation

distinct lattice fringes (Fig. 2d). A typical interplanar spacing of $0.84 \mathrm{~nm}$ is matching well with the $\left(\begin{array}{lll}1 & 0 & 0\end{array}\right)$ plane of hexagonal $\mathrm{Mg}_{2} \mathrm{Al}_{4} \mathrm{Si}_{5} \mathrm{O}_{18}$ crystal, according to the fast Fourier transform (FFT) image viewing along [0-21] zone axis (Fig. 2e, f). There are no lattice fringes at the edge of the crystal (the region surrounded by yellow dotted line in Fig. S5), suggesting it is the tiny remaining glassy phase. High-angle annular dark-field scanning TEM (HAADFSTEM) observations and the corresponding element mappings (Fig. 2g, h) were also carried out to characterize the microstructure. As observed in element mappings, the $\mathrm{Mg}, \mathrm{Al}, \mathrm{Si}$, and $\mathrm{O}$ are homogeneously distributed over the crystal, whereas the $\mathrm{Mg}, \mathrm{Al}$, and $\mathrm{O}$ are rich over the glassy phase. The absence of $\mathrm{Si}$ in the remaining glassy suggests the almost totally depletion of $\mathrm{Si}$ in the process of $\mathrm{Mg}_{2} \mathrm{Al}_{4} \mathrm{Si}_{5} \mathrm{O}_{18}$ crystallize propagation.

\section{Site occupancy and optical properties}

Figure 3a depicts the crystal structure of hexagonal $\mathrm{Mg}_{2} \mathrm{Al}_{4} \mathrm{Si}_{5} \mathrm{O}_{18}: \mathrm{Eu}^{2+}$. The $\mathrm{Al}$ and $\mathrm{Si}$ atoms are disorderly distributed over two sets of tetrahedral sites to form (Al1/
$\mathrm{Si} 1) \mathrm{O}_{4}$ and $(\mathrm{Al} 2 / \mathrm{Si} 2) \mathrm{O}_{4}$ tetrahedrons. The $\mathrm{Mg}$ atoms are surrounded by the $(\mathrm{Al} / \mathrm{Si})_{6} \mathrm{O}_{18}$-type 6 -membered rings, and are six-fold coordinated to form $\mathrm{MgO}_{6}$ octahedrons (Fig. 3b). Comparing the ionic radius of $\mathrm{Eu}^{2+}$ ( $r_{6 \text {-coord. }}=$ $1.17 \AA)$ with that of $\mathrm{Mg}^{2+}\left(r_{6 \text {-coord. }}=0.72 \AA\right)$ suggests that it is unlikely for $\mathrm{Eu}^{2+}$ to replace $\mathrm{Mg}^{2+}$ because their radius difference is as high as $\sim 62.5 \%$, which is far beyond the limits of the Hume-Rothery rules for atomic substitution $^{38}$.

There are large vacant channels running parallel to the $c$-axis in the $\mathrm{Mg}_{2} \mathrm{Al}_{4} \mathrm{Si}_{5} \mathrm{O}_{18}$ (Fig. S6), and it has been reported that the channels have the capability to accommodate a variety of cation ions ${ }^{39}$. Therefore, one can easily speculate that the $\mathrm{Eu}^{2+}$ ions inserted at the channel sites. Figure S7a, b demonstrate the two kinds of strikingly different channel sites in the host, namely, $z=0.0$ or 0.5 site with six-fold coordinated planar oxygen, another is $z=0.25$ or 0.75 with 12 -fold coordinated oxygen ${ }^{32}$. To understand the site occupation, DFT calculations were conducted to evaluate the rel ative occurrence probabilities of $\mathrm{Eu}^{2+}$ substitutions at various sites. Before 
doing so, the occupational disorder at Al1/Si1 (6f) and $\mathrm{Al} 2 / \mathrm{Si} 2(12 l)$ sites needs to be modeled first. In accordance with the Rietveld results (Table S3), the occupancy ratios at the two sites were approximated by Al1/Si1 $=5 / 1$ and $\mathrm{Al} 2 / \mathrm{Si} 2=1 / 3$. The resultant atomic composition is consistent with the chemical formula. With this approximation, there are totally 1320 different atomic configurations of the unit cell, which when the crystal symmetry is taken into account ${ }^{40}$, reduces to 57 crystallographically independent configurations that are necessary for calculations. The relative occurrence probability $\left(P_{\mathrm{i}}\right)$ of each configuration with multiplicity $i$ was evaluated with $P_{\mathrm{i}}=\frac{1}{Z_{\mathrm{tot}}} \Omega_{\mathrm{i}} \exp \left(-\frac{E_{\mathrm{i}}}{k T}\right)(i=1, \ldots, 57)$, where $\mathrm{Z}_{\text {tot }}$ is the partition function, $E_{\mathrm{i}}$ is the relative DFT total energy, $k$ is the Boltzmann constant, and $T$ is the synthesis temperature of the material. It was found that five distinct configurations dominate the configurational ensemble, with the relative occurrence probabilities $P=0.624,0.132,0.076,0.074$, and 0.062 , respectively. For the other inequivalent configurations, each $P<0.006$. Based on this, the undoped unit cells with these five configurations were employed for subsequent investigation of $\mathrm{Eu}^{2+}$ site occupations.

For $\mathrm{Mg}_{2} \mathrm{Al}_{4} \mathrm{Si}_{5} \mathrm{O}_{18}: \mathrm{Eu}^{2+}$, we have considered two kinds of $\mathrm{Eu}^{2+}$ substitutions, that is, isovalent substitution at the host $\mathrm{Mg}^{2+}$ site $\left(\mathrm{Eu}_{\mathrm{Mg}}\right)$, and occupations within the vacant channel $\left(\mathrm{Eu}_{\mathrm{vac}}\right)$ at $z=0.0,0.25,0.5$, and 0.75 with a $\mathrm{Mg}$ vacancy $\left(\mathrm{V}_{\mathrm{Mg}}\right)$ or two antisite defects $\left(2 \mathrm{Al}_{\mathrm{Si}}\right)$ as the charge compensator. The DFT calculations revealed that the defect formation energies of $\mathrm{Eu}_{\mathrm{Mg}}$ and $\mathrm{Eu}_{\mathrm{vac}}-\mathrm{V}_{\mathrm{Mg}}$ are at least by $2.5 \mathrm{eV}$ higher than the most stable $\mathrm{Eu}_{\mathrm{vac}}-2 \mathrm{Al}_{\mathrm{Si}}$ complexes. This means that $\mathrm{Eu}_{\mathrm{Mg}}$ and $\mathrm{Eu}_{\mathrm{vac}}-\mathrm{V}_{\mathrm{Mg}}$ are unlikely to occur compared to $\mathrm{Eu}_{\mathrm{vac}}-2 \mathrm{Al}_{\mathrm{Si}}$, and will thus be discarded in the following discussion. For $\mathrm{Eu}_{\mathrm{vac}}$ at each site within the vacant channel, there are $45 \mathrm{Al}_{\mathrm{Si}}-\mathrm{Al}_{\mathrm{Si}}$ combinations in a given unit cell. As such, for the five most probable atomic configurations of unit cell each with four substituted sites $(z)$, a total of $900 \mathrm{Eu}^{2+}$-incorporated different cells have been calculated by DFT to explore the site preference of $\mathrm{Eu}^{2+}$ within the vacant channel. The results show that $\mathrm{Eu}^{2+}$ locations at $z=0.25$ and 0.75 sites are unstable in that the $\mathrm{Eu}^{2+}$ initially positioned at these sites would relax into $z=0.0$ or 0.5 sites during DFT geometry optimization. The most stable configurations (to within $100 \mathrm{meV}$ ) have $\mathrm{Eu}^{2+}$ located at $z=0.0$ or 0.5 site, surrounded by six $\mathrm{O}$ in a quasi-planar structure in the first coordination shell and $2 \mathrm{Al}+4 \mathrm{Si}$ or $3 \mathrm{Al}+3 \mathrm{Si}$ atoms randomly distributed in the second coordination shell, which is in line with the occupational disorder of $\mathrm{Al}$ / $\mathrm{Si}$ sites. Therefore, DFT calculations predict that most $\mathrm{Eu}^{2+}$ ions are located at $z=0.0$ or 0.5 sites with six-fold coordination within the vacant channel (Fig. 3a, c).

To experimentally determine the location of $\mathrm{Eu}$ and its valance state, extended $\mathrm{X}$-ray absorption fine structure (EXAFS) at the $\mathrm{Eu} L_{3}$ edge was measured. Figure 3d shows the $\mathrm{Eu} L_{3}$ edge $\mathrm{X}$-ray absorption near-edge structure (XANES) spectra of the composite phosphor and $\mathrm{Eu}_{2} \mathrm{O}_{3}$. The absorption energy at about 6975 and $6982 \mathrm{eV}$ are attributed to $2 p_{3 / 2} \rightarrow 5 d$ transitions of $\mathrm{Eu}^{2+}$ and $\mathrm{Eu}^{3+}$, respectively. The absence of $6982 \mathrm{eV}$ peak for the composite suggests that the valence state of $\mathrm{Eu}$ in the $\mathrm{Mg}_{2} \mathrm{Al}_{4} \mathrm{Si}_{5} \mathrm{O}_{18}$ is in divalent oxidation state, which is also beneficial for achieving high efficiency luminescence. The EXAFS spectra were processed in Athena (version 0.9.25) for background, pre-edge line, and post-edge line calibrations. Then Fourier transformed fitting was carried out in Artemis (version 0.9.25). The $k^{3}$ weighting, $k$-range of 3-9 $\AA^{-1}$ and $R$ range of $1-4 \AA$ were used for the fitting. The four structure parameters, including coordination number $(\mathrm{CN})$, bond length $(R)$, Debye-Waller factor $\left(\sigma^{2}\right)$, and $E_{0}$ shift $\left(\Delta \mathrm{E}_{0}\right)$ were fitted without anyone was fixed, constrained, or correlated. The reciprocal space $k^{3}$ weighting EXAFS and the corresponding Fourier transformed spectra are shown in Fig. 3e. The fitted structure parameters are presented in Table S5. The spectra were well fitted ( $R$ factor $=0.006$ ), with the fitted $\mathrm{CN}$ in the first coordinated shell is $6.5 \pm 1.6$, and $R$ for $\mathrm{Eu}-\mathrm{O}$ bond is $2.60 \pm 0.03 \AA$. This strongly supports that $\mathrm{Eu}^{2+}$ incorporates in the $z=0.0$ or 0.5 channel sites as the fitted parameters are consistent well with that of the non-doped $\mathrm{Mg}_{2} \mathrm{Al}_{4} \mathrm{Si}_{5} \mathrm{O}_{18}$ (the diameter of the channel is $\sim 5.6 \AA$, and those sites are six-fold coordination), in line with the DFT calculations discussed above. Indeed, cordierite is an incredible phosphor host, and the blue emission in $\mathrm{Mg}_{2} \mathrm{Al}_{4} \mathrm{Si}_{5} \mathrm{O}_{18}$ : $\mathrm{Eu}^{2+}$ was also reported previously, and the origin of the $\mathrm{Eu}^{2+}$ occupation is still a controversial issue $^{29,30}$. As such, one can still expect future work to address some important findings on this topic.

Figure $3 \mathrm{f}$ displays the photoluminescence excitation and emission spectra of $\mathrm{Mg}_{2} \mathrm{Al}_{4} \mathrm{Si}_{5} \mathrm{O}_{18}: \mathrm{Eu}^{2+}$ composite phosphor measured at room temperature. It exhibits bright red-light emission under near UV light irradiation (inset of Fig. 3f). Under $450 \mathrm{~nm}$ blue light excitation, the PL spectrum consists a broad band emission with the maximum peak at $\sim 620 \mathrm{~nm}$, ascribed to parity-allowed electric dipole $\mathrm{Eu}^{2+}: 4 f^{6} 5 d \rightarrow 4 f^{7}\left({ }^{8} S_{7 / 2}\right)$ transition. The excitation spectra by monitoring $620 \mathrm{~nm}$ emission exhibits a broad band with the maximum peak at around $450 \mathrm{~nm}$; therefore, the phosphor is blue light highly excitable. Noteworthy, the realization of $\mathrm{Eu}^{2+}$ red emission in oxidebased host is known a challenge task. Recently, Stefańska et al. observed the red emission in $\mathrm{Mg}_{2} \mathrm{Al}_{4} \mathrm{Si}_{5} \mathrm{O}_{18}: \mathrm{Eu}^{2+}$ phosphor powder ${ }^{32}$, which was, however, accompanied with the strong blue emission. PL decay of the $4 f^{6} 5 d$ state displays a nearly single exponent decay (Fig. S8), and time-resolved PL spectra shows an insignificant variation of emission profile at as time prolongs from 7 to $56 \mu \mathrm{s}$ (Fig. S9), suggesting a homogeneous crystal field environment around $\mathrm{Eu}^{2+}$ in $\mathrm{Mg}_{2} \mathrm{Al}_{4} \mathrm{Si}_{5} \mathrm{O}_{18}$ lattice. The derived 

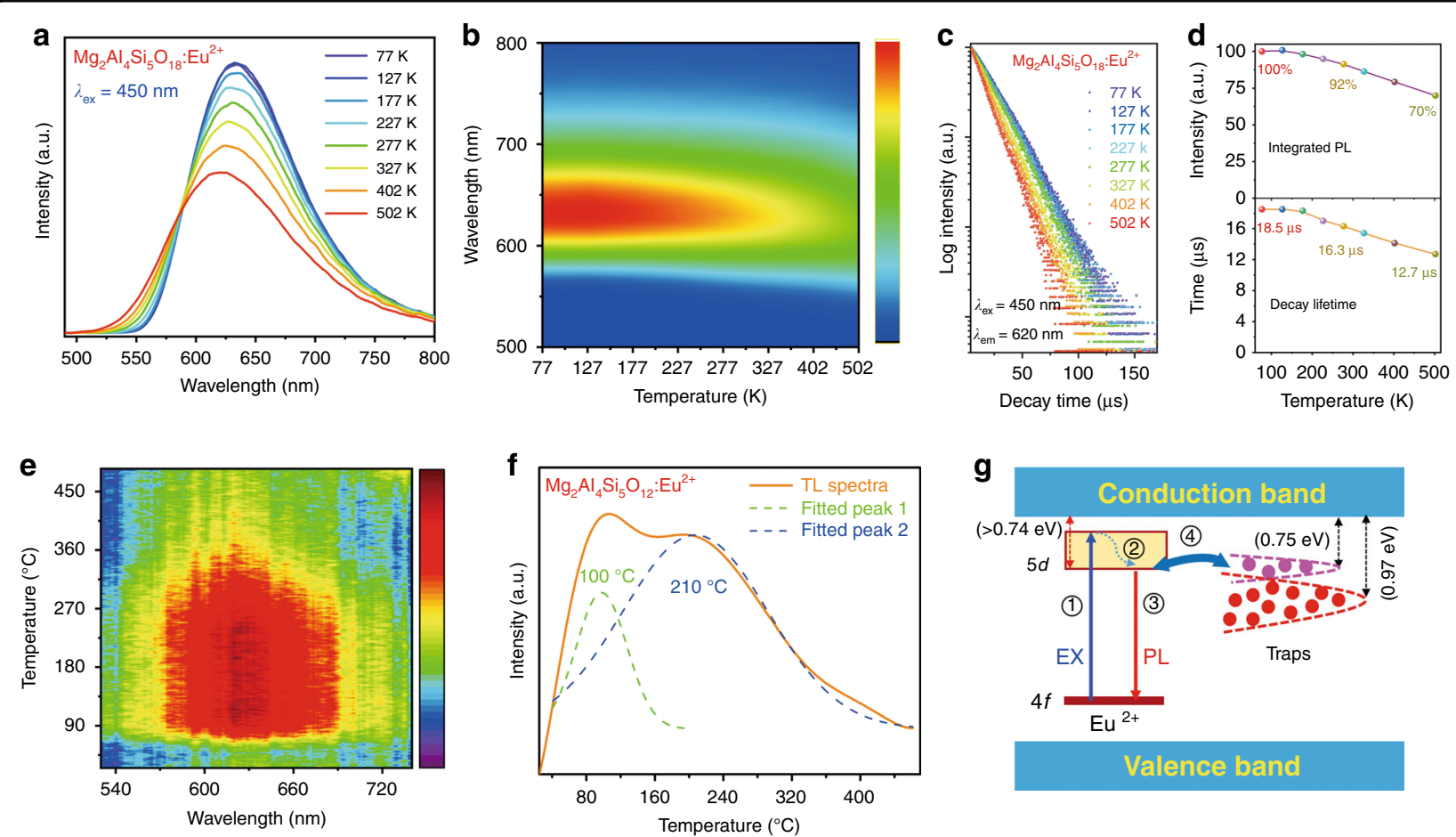

Fig. 4 Thermal emission properties of the $\mathrm{Mg}_{2} \mathrm{Al}_{4} \mathrm{Si}_{5} \mathrm{O}_{18}: \mathrm{Eu}^{2+}$ composite phosphor. $\mathbf{a}$, $\mathbf{b}$ Emission spectra of $\mathrm{Mg}_{2} \mathrm{Al}_{4} \mathrm{Si}_{5} \mathrm{O}_{18}: \mathrm{Eu}^{2+}\left(\lambda_{\mathrm{ex}}=450 \mathrm{~nm}\right)$ in the temperature range $77-502 \mathrm{~K}$. c Decay curves of $\mathrm{Mg}_{2} \mathrm{Al}_{4} \mathrm{Si}_{5} \mathrm{O}_{18}: \mathrm{Eu}^{2+}\left(\lambda_{\text {ex }}=450 \mathrm{~nm}, \lambda_{\mathrm{em}}=620 \mathrm{~nm}\right)$ in the temperature range $77-502 \mathrm{~K}$. $\mathbf{d}$ Normalized integrated PL intensity and decay time as function of temperature. TL glow curves of the $\mathrm{Mg}_{2} \mathrm{Al}_{4} \mathrm{Si}_{5} \mathrm{O}_{18}$ :Eü ${ }^{2+}$ composite phosphor, e three-dimensional TL $\mathbf{f}$ two-dimensional TL spectra. $\mathbf{g}$ Schematic illustration of the possible mechanism of the slow decay of Eu ${ }^{2+} 5 d$ state in $\mathrm{Mg}_{2} \mathrm{Al}_{4} \mathrm{Si}_{5} \mathrm{O}_{18}$, showing the processes of electron (1) excitation, (2) nonradiative relaxation, (3) emission, (4) trapping, and detrapping

luminescence decay time is $15.4 \mu \mathrm{s}$, which is unexpectedly long compared to those (about $1.0 \pm 0.5 \mu \mathrm{s}^{41}$ ). The origin of this slow decay will be discussed later. Under $450 \mathrm{~nm}$ blue light excitation, the composite phosphor exhibits a high internal/external quantum efficiency of $94.5 / 70.6 \%$ (Fig. S10), guaranteeing its practical application.

As is known, the thermal shock of laser during the application is extreme, with the laser pump power of even a few watts into sub-millimeter spot can easily raise local temperature well into hundreds of degrees Celsius. Therefore, thermally stable properties are necessarily required in laser applications. Temperature-dependent XRD patterns (Fig. S11) verify the phase and physicochemical stability of the as-fabricated $\mathrm{Mg}_{2} \mathrm{Al}_{4} \mathrm{Si}_{5} \mathrm{O}_{18}: \mathrm{Eu}^{2+}$ composite. The emission spectra $\left(\lambda_{\text {ex }}=450 \mathrm{~nm}\right)$ in Fig. $4 \mathrm{a}, \mathrm{b}$ are gradually blue-shifted and broadened (Fig. S12) with increasing temperature, as commonly observed for $\mathrm{Eu}^{2+}$ emission. The blue shift is caused by lattice thermally expansion (Fig. S13), which increases the $\mathrm{Eu}-\mathrm{O}$ distance and thus results in a smaller crystal field splitting and a decreased covalency. The spectrum broadening is essentially due to the enhanced electron-phonon interaction at high temperature, inducing the electron thermally populate to higher vibrational levels. The PL decay curves at various temperature are close to single- exponential (Fig. 4c). The composite exhibits excellent thermal stable luminescence; the integrated PL intensity at $423 \mathrm{~K}\left(150{ }^{\circ} \mathrm{C}\right)$ remains $\sim 78 \%$ of that at $70 \mathrm{~K}$ (Fig. $4 \mathrm{~d}$ ). The quenching temperature $\left(T_{0.5}\right)$, namely, the temperature at which the emission intensity (or decay time) drops to $50 \%$ of the low-temperature value, is higher than $500 \mathrm{~K}$ (Fig. 4d), from which the activation energy $\left(E_{\mathrm{a}}\right)$ for thermal quenching can be estimated to be larger than 0.74 $\mathrm{eV}^{42}$. The thermal conductivity is measured to be $\sim 2.2 \mathrm{~W}$ $\mathrm{m}^{-1} \mathrm{~K}^{-1}$, larger than that of the organic binder of $\sim$ $0.1-0.2 \mathrm{~W} \mathrm{~m}^{-1} \mathrm{~K}^{[-112}$ and the co-sintered PiG of $\sim 1 \mathrm{~W}$ $\mathrm{m}^{-1} \mathrm{~K}^{[-113}$. In addition, thanks to the robust of inorganic aluminosilicate matrices, the phosphor also shows good anti-moisture properties (Fig. S14). All those results indicate the $\mathrm{Mg}_{2} \mathrm{Al}_{4} \mathrm{Si}_{5} \mathrm{O}_{18}: \mathrm{Eu}^{2+}$ phosphor is robust enough to withstand the thermal shock of blue LD and humidity during the applications.

Figure $4 \mathrm{e}$ shows the three-dimensional thermoluminescence (TL) spectra of $\mathrm{Mg}_{2} \mathrm{Al}_{4} \mathrm{Si}_{5} \mathrm{O}_{18}: \mathrm{Eu}^{2+}$ composite phosphor. The TL emission peaked at $\sim 620 \mathrm{~nm}$, confirming that the defect-trapped charge carriers were thermally released to generate excited $\mathrm{Eu}^{2+}$ giving rise to the red emission. The two-dimensional TL spectrum covers a wide temperature range from 30 to $500{ }^{\circ} \mathrm{C}$ (Fig. $4 \mathrm{f}$ ), indicating a continuous distribution of defect trap 
depth. The spectrum can be fitted by two Gaussian bands peaking at 100 and $210{ }^{\circ} \mathrm{C}$, for which the trap depths $\left(E_{\mathrm{T}}\right)$ can be estimated to be 0.76 and $0.97 \mathrm{eV}$, respectively, on the basis of the approximate equation $E_{\mathrm{T}}=T / 500$, where the temperature $T$ is in units of kelvin. These defects could be oxygen vacancies, which have been commonly observed in oxides synthesized in reducing atmosphere and confirmed to be responsible for thermal behavior of $\mathrm{Eu}^{2+}$ luminescence ${ }^{43}$.

As mentioned earlier, the long decay time $(15.4 \mu \mathrm{s})$ of $\mathrm{Eu}^{2+}$-related red emission is striking. Dorenbos has proposed the requirements to be met for $\mathrm{Eu}^{2+}$-related anomalous emission, namely, a much larger Stokes shift, a broad emission band, and a longer decay time than the normal $\mathrm{Eu}^{2+}$ emission $^{44}$. This anomalous emission originates from the close proximity between the excited $\mathrm{Eu}^{2+}$ $5 d$ emitting level and the bottom of the host conduction band. Upon $\mathrm{Eu}^{2+} 4 f \rightarrow 5 d$ excitation, the electron in the $5 d$ level delocalizes into the host band state generating a $\mathrm{Eu}^{3+}$-trapped excitonic state, from which the transition to the $\mathrm{Eu}^{2+} 4 f^{7}$ ground state leads to a strongly red-shifted emission compared to the normal $5 d \rightarrow 4 f$ emission. In the present case of $\mathrm{Mg}_{2} \mathrm{Al}_{4} \mathrm{Si}_{5} \mathrm{O}_{18}: \mathrm{Eu}^{2+}$, however, the red emission is considered to be normal because (1) the Stokes shift $\left(3700 \mathrm{~cm}^{-1}\right)$ is not large, (2) the emission band (FWHM $=2700 \mathrm{~cm}^{-1}$ ) is not broad, and (3) the emitting level is well below the host conduction band $\left(E_{\mathrm{a}}\right.$ $>0.74 \mathrm{eV}$ ). If so, what is the cause for the surprising longdecay of the red $5 d \rightarrow 4 f$ emission?

In $\mathrm{Mg}_{2} \mathrm{Al}_{4} \mathrm{Si}_{5} \mathrm{O}_{18}: \mathrm{Eu}^{2+}$, the TL measurement revealed a distribution of defect trap levels with main peaks at 0.76 and $0.97 \mathrm{eV}$ below the host conduction band edge (Fig. $4 \mathrm{~g})$. The energy positions of these defect levels are close to that of $\mathrm{Eu}^{2+} 5 d$ emitting level $(>0.74 \mathrm{eV}$ below the host conduction band edge). At room temperature, the electrons trapped at these defect levels can be thermally activated to release into $\mathrm{Eu}^{2+} 5 d$ levels, which results in $5 d$ $\rightarrow 4 f$ emission with a long decay time. At lower temperature the luminescence decay would be longer in view of the thermally activated electron transfer, consistent with experimental observations (Fig. 4c). A schematic representation of the luminescence mechanism is depicted in Fig. 4g. Upon $450 \mathrm{~nm}$ irradiation, $\mathrm{Eu}^{2+}$ is excited from the $4 f$ ground state to higher $5 d$ levels (process 1 ), which then relaxes nonradiatively to the lowest $5 d$ level (process 2). From this excited level, the $5 d$ electron can return back to the $4 f$ ground state by emitting a red photon (process 3 ), or transfer to nearby electron-trapping defects by direct tunneling (process 4) due the close proximity between the $\mathrm{Eu}^{2+} 5 d$ and defect levels. During the decay-time measurement of the $5 d \rightarrow 4 f$ emission, the electron trapped at the defects will transfer back (process 4 ) to the emitting $5 \mathrm{~d}$ level, leading to luminescence decay time much longer than the normal case.

\section{Demonstration of application for LD lighting}

The blue laser driven red lighting device was constructed by coupling the $\mathrm{Mg}_{2} \mathrm{Al}_{4} \mathrm{Si}_{5} \mathrm{O}_{18}: \mathrm{Eu}^{2+}$ composite with $445 \mathrm{~nm}$ blue laser diode aiming to evaluate its potential application for high power lighting. As plots in Fig. 5a, b, the emission intensity of the composite increases monotonously as the laser power density increases from 0.25 to $3.25 \mathrm{~W} \mathrm{~mm}^{-2}$, beyond which luminescence saturation occurs. The maximum luminous flux and luminous efficiency achieved for $\mathrm{Mg}_{2} \mathrm{Al}_{4} \mathrm{Si}_{5} \mathrm{O}_{18}$ : $\mathrm{Eu}^{2+}$ composite phosphor is $\sim 274 \mathrm{~lm}$ and $54 \mathrm{~lm} \mathrm{~W}^{-1}$, respectively. The time-dependent emission spectra under a fixed power density of $1.5 \mathrm{~W} \mathrm{~mm}^{-2}$ (Fig. S15), and the corresponding luminous flux (Fig. $5 \mathrm{c}$ ) demonstrate the composite phosphor is stable enough in practice application. We also made a performance comparison between our composite and the previously reported red CaAlSiN ${ }_{3}$ : $\mathrm{Eu}^{2+}$ ceramic synthesized by using the state-of-art red $\mathrm{CaAlSiN}_{3}: \mathrm{Eu}^{2+}$ phosphor. As shown in Fig. 5d, the maximum luminous flux and luminous efficiency achieved for $\mathrm{CaAlSiN}_{3}: \mathrm{Eu}^{2+}$ ceramic is about $203 \mathrm{~lm}$ and $41 \mathrm{~lm}$ $\mathrm{W}^{[-122}$, which is inferior to our reported photoelectric properties and actually the photoelectric properties realized in $\mathrm{Mg}_{2} \mathrm{Al}_{4} \mathrm{Si}_{5} \mathrm{O}_{18}: \mathrm{Eu}^{2+}$ composite is almost the highest rank among red bulk phosphors. Anyway, all those results suggest that the $\mathrm{Mg}_{2} \mathrm{Al}_{4} \mathrm{Si}_{5} \mathrm{O}_{18}: \mathrm{Eu}^{2+}$ holds potential for addressing the lack of commercially available all-inorganic red-emitting bulk color converter.

Finally, we constructed the blue laser driven white lighting device by using a stack package configuration, in which the commercial LuAG:Ce ${ }^{3+}$ ceramic serving as a green color converter is stack packed with red $\mathrm{Mg}_{2} \mathrm{Al}_{4^{-}}$ $\mathrm{Si}_{5} \mathrm{O}_{18}: \mathrm{Eu}^{2+}$ to form white light (Fig. 6a, b). Figure 6c demonstrates the emission spectra of the white lighting device operating under the incident power density of $0.25 \mathrm{~W} \mathrm{~mm}^{-2}$. The device exhibits a low correlated color temperature (CCT) of $4146 \mathrm{~K}$, high color render index $\left(R_{\mathrm{a}}=85.2, R_{9}=64.5\right)$, and CIE chromaticity coordinates of $(0.364,0.333)$, which is much better than the properties of the YAG: $\mathrm{Ce}^{3+}$-based laser driven white lighting featuring a high CCT $(>7500 \mathrm{~K})$ and a low $R_{a}(<75)^{15}$. The incident power density dependent emission spectra, luminous flux and luminous efficiency are presented in Fig. 6d, e and Table S6. With the increment of pumping power density from 0.25 to $4 \mathrm{~W} \mathrm{~mm}{ }^{-2}$, the output of the white light is get enhanced gradually, and the CIE chromaticity coordinates at various power densities are near at Planckian locus curve (Fig. 6f). The maximum luminous flux $(480 \mathrm{~lm})$ and luminous efficiency $\left(94.1 \mathrm{~lm} \mathrm{~W}^{-1}\right)$ realized in our white lighting device is relatively low compared with that of the YAG:Ce ${ }^{3+}$-based laser driven white lighting device, partly due to the output of green light is blocked by the red composite. We think there is a large space to improve it via carefully design packing 

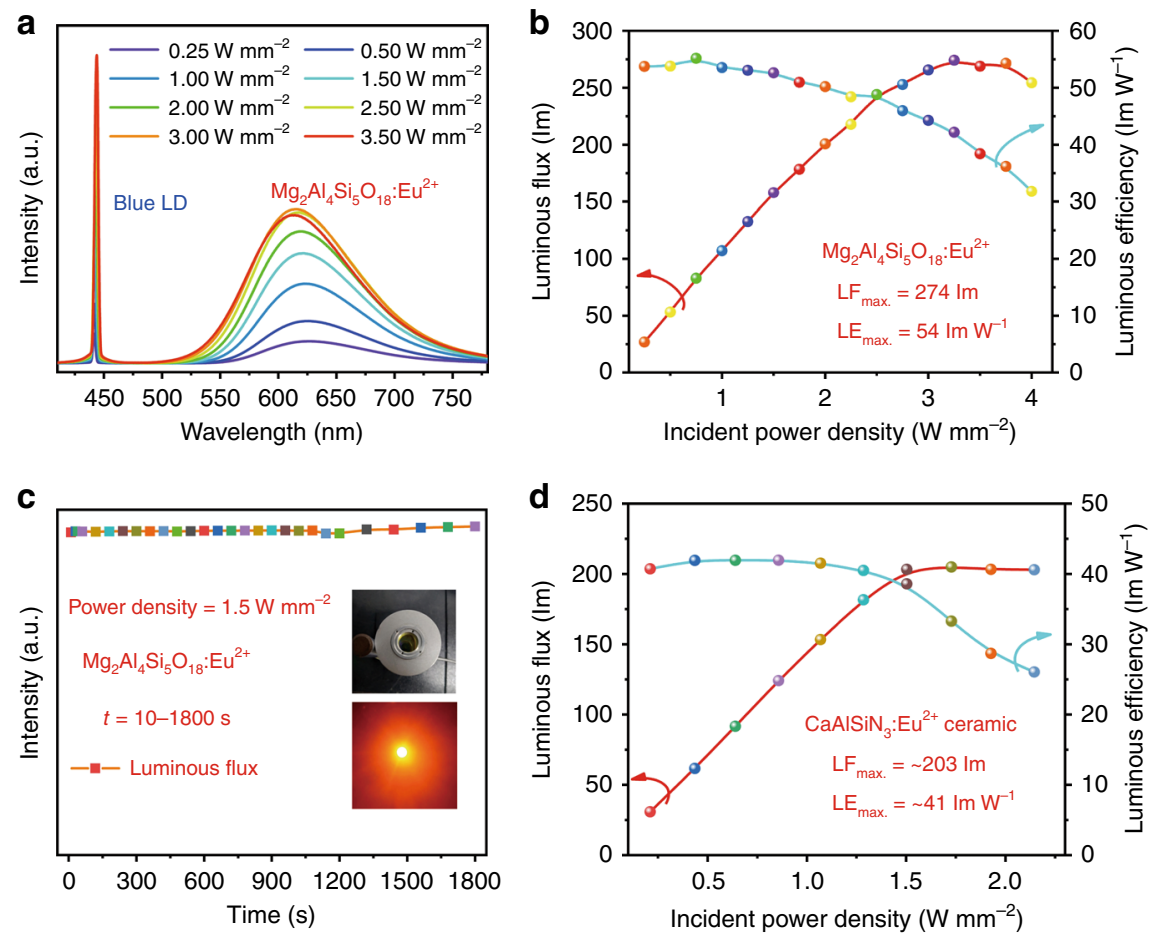

Fig. 5 Photoelectric properties of the LD driven red-emitting device constructed by using $\mathrm{Mg}_{2} \mathrm{Al}_{4} \mathrm{Si}_{5} \mathrm{O}_{18}: \mathrm{Eu}^{2+}$ phosphor. The power densitydependent $\mathbf{a}$ luminescent spectra $\mathbf{b}$ luminous flux and luminous efficiency of $\mathrm{Mg}_{2} \mathrm{Al}_{4} \mathrm{Si}_{5} \mathrm{O}_{18}: \mathrm{Eu}^{2+}$ composite under the excitation of $445 \mathrm{~nm}$ blue laser. c Time-dependent luminous flux of the composite at a fixed incident power density of $1.5 \mathrm{~W} \mathrm{~mm}^{-2}$, the inset show the photograph of red LD device. $\mathbf{d}$ The incident power density-dependent luminous flux and luminous efficiency of the CaAlSiN $\mathrm{Eu}^{2+}$ ceramic $^{22}$

configuration or material design, for example, by further optimization of the transparency of the red composite, or even fabrication of $\mathrm{LuAG}: \mathrm{Ce}^{3+} / \mathrm{Mg}_{2} \mathrm{Al}_{4} \mathrm{Si}_{5} \mathrm{O}_{18}: \mathrm{Eu}^{2+}$ binary composite.

\section{Conclusions}

In summary, we report a facile elaboration of new type of red-emitting $\mathrm{Mg}_{2} \mathrm{Al}_{4} \mathrm{Si}_{5} \mathrm{O}_{18}: \mathrm{Eu}^{2+}$ composite phosphor based on glass relaxation and crystallization of a composition specially designed aluminosilicate glass at ambient conditions. The optical properties realized here are especially surprising, because red phosphor exhibits near unity luminescence efficiency and stable emission against temperature, which enables it readily meets the highpower laser driven lighting applications. Our demonstration represents the first proof-of-principle glass crystallization of red-emitting composite phosphor, and we believe that it will provide a great step toward the advancement of new materials discovery of the solid-state lighting technology for the new photonic applications.

\section{Methods}

\section{Materials and preparation}

The precursor glass (PG) with nominal composition of $2 \mathrm{MgO}-\mathrm{Al}_{2} \mathrm{O}_{3}-3 \mathrm{SiO}_{2}$ was prepared via melt-quenching method, and a small amount of $\mathrm{Eu}_{2} \mathrm{O}_{3}$ was introduced into the PG to serve as the source of $\mathrm{Eu}^{2+}$ dopant. In a detailed preparation procedure, the raw materials of $\mathrm{MgO}$ (1.1612 g), $\mathrm{Al}_{2} \mathrm{O}_{3}(2.039 \mathrm{~g}), \mathrm{SiO}_{2}(3.605 \mathrm{~g})$, and $\mathrm{Eu}_{2} \mathrm{O}_{3}$ (optimal doping amount of $0.05 \mathrm{~g}$ ) were weighted, mixed, and ground thoroughly in an agate mortar. The mixture was transferred into corundum crucible, and then fully melted at $1550{ }^{\circ} \mathrm{C}$ for $4 \mathrm{~h}$ under a reducing atmosphere $\left(\mathrm{N}_{2} / \mathrm{H}_{2}=80 \% / 20 \%\right)$ in the tube furnace. The melt was cooled naturally to $750{ }^{\circ} \mathrm{C}$ in the tube furnace to form PG and further annealed at $750{ }^{\circ} \mathrm{C}$ for $5 \mathrm{~h}$ to relinquish the internal stress. The red-emitting $\mathrm{Mg}_{2} \mathrm{Al}_{4} \mathrm{Si}_{5} \mathrm{O}_{18}: \mathrm{Eu}^{2+}$ bulk composite was prepared via heat treatment of the $\mathrm{PG}$ at $1120{ }^{\circ} \mathrm{C}$ for $15 \mathrm{~min}$ under a reducing atmosphere $\left(\mathrm{N}_{2} / \mathrm{H}_{2}\right.$ $=80 \% / 20 \%)$. However, blue-emitting $\mathrm{Mg}_{2} \mathrm{Al}_{4} \mathrm{Si}_{5} \mathrm{O}_{18}: \mathrm{Eu}^{2+}$ bulk composite can be also prepared by using the same method, while with the different PG composition, $2 \mathrm{MgO}-\mathrm{Al}_{2} \mathrm{O}_{3}-4 \mathrm{SiO}_{2}$. The obtained PG and composite phosphor were cut and polished before characterizations.

Worthy to mention, the glass melt liquid usually needs to be cooled down at a sufficiently high rate to escape crystallization, so that the liquid melt should be taken out from furnace at high temperature and quenched as fast as possible, which poses extra-cost and dangerous. Commendably, the PG in our case can be fabricated in a more convenient way of melt slowly cooled in the furnace. This added advantage is benefited from a relatively high 

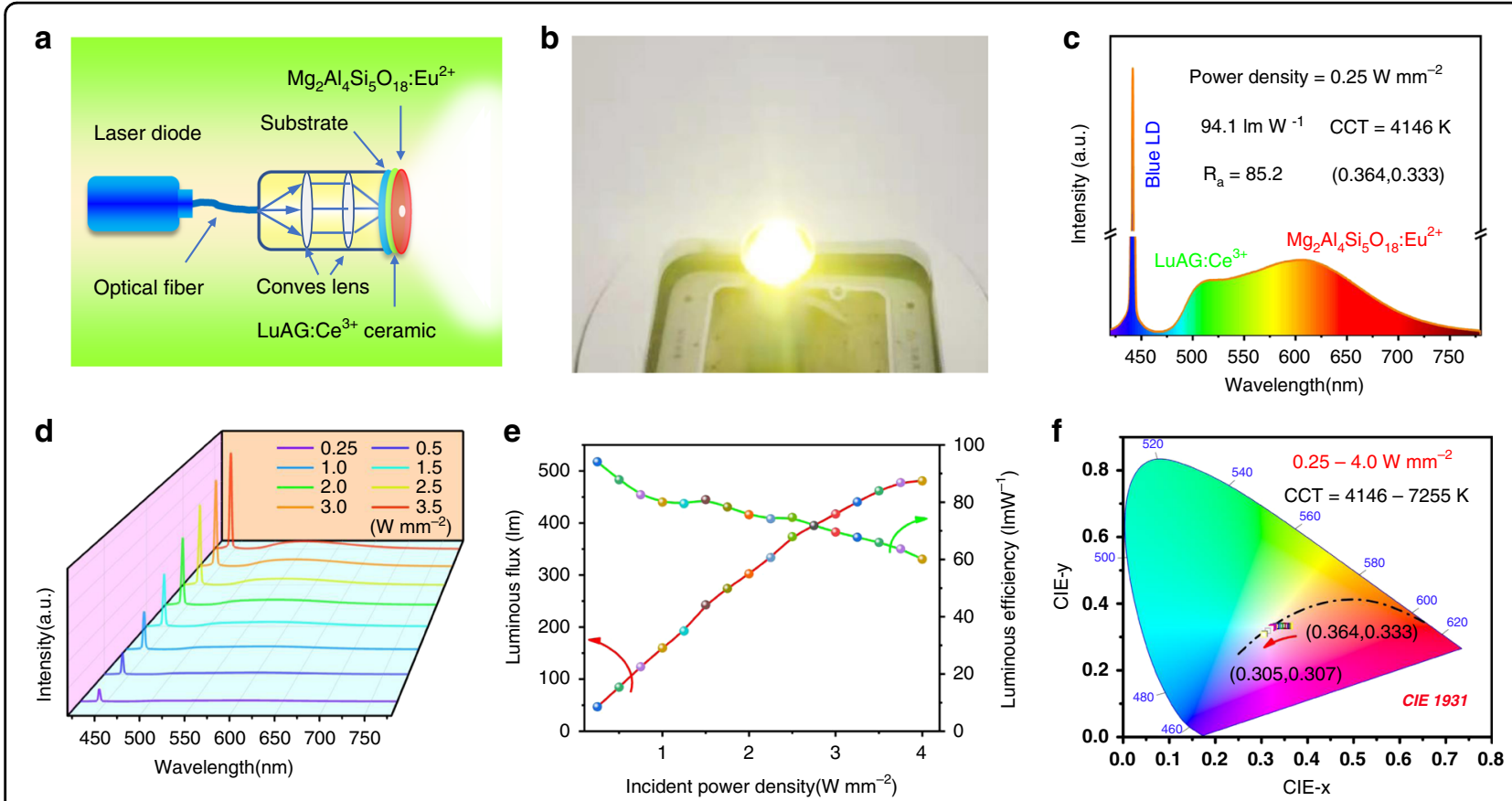

Fig. 6 Photoelectric properties of the LD driven white lighting device. a Schematic illustration of the construction of blue laser driven white light device. $\mathbf{b}$ The photograph of the constructed laser driven white light taken under its operation. $\mathbf{c}$ The emission spectra of the constructed laser driven light device under the incident power density of $0.25 \mathrm{~W} \mathrm{~mm}^{-2}$. Incident power density-dependent $\mathbf{d}$ emission spectra, e luminous flux and luminous efficiency, $\mathbf{f} \mathrm{ClE}$ coordinates of the laser driven lighting device

viscosity $(\tau)$ of silicate melt and a steep increase of viscosity with decreasing temperature (Fig. 1a), leading to large-scale atomic rearrangements are no longer possible.

\section{Characterization}

The thermodynamic parameters of the PG were measured by a DTA method on the NETZSCH STA 449C with the heating rate of $10 \mathrm{~K} \mathrm{~min}^{-1}$. The thermal conductivity was measured on Physical Property Measurement System (ppms-9). The phase identifications were performed by using powder X-ray diffraction, on Aeris Xray diffractometer operating at $40 \mathrm{KV}$ and $15 \mathrm{~mA}$. Synchrotron XRD pattern for Rietveld analysis was collected at high-resolution powder diffraction end station $(\lambda=0.82656 \AA, 15 \mathrm{KeV})$ and MYTHEN $24 \mathrm{~K}$ detector. The Eu valance state was examined by $\mathrm{Eu} L_{3}$-edge of Xray absorption near-edge structure spectroscopy in fluorescence mode. The Rietveld refinement was performed by using TOPAS 4.2 software. The SEM image and elemental mapping of the PG were acquired on HITACHI Regulus 8100 scanning electron microscope equipped with an energy-dispersive X-ray spectroscopy (EDS) system. Scanning transmission electron microscopy (STEM) image were taken on a FEI aberration-corrected Titan Cubed S-Twin transmission electron microscope operating in a high-angle annular dark-field (HAADF) mode equipped with an energy dispersive $\mathrm{X}$-ray spectroscope operated at $200 \mathrm{KV}$. High-resolution transmission electron microscopy (HRTEM) image and selected electron diffraction (SAED) were taken on transmission electron microscope (JEOL, JEM-2100 and JEM-2010) operating at $200 \mathrm{KV}$. A Bruker vector 33 spectrometer is used for the measurement of Fouriertransform infrared (FTIR) spectra. The PL and PLE spectra, quantum efficiency, temperature-dependent PL, and temperature-dependent fluorescent decay curves were all recorded on an Edinburgh Instrument FLS1000 spectrofluorometer equipped with a xenon lamp $(450 \mathrm{~W})$ as the excitation source. The photoelectric properties of the red emitting device fabricated by $\mathrm{Mg}_{2} \mathrm{Al}_{4} \mathrm{Si}_{5} \mathrm{O}_{18}: \mathrm{Eu}^{2+}$ composite under the high-power $445 \mathrm{~nm}$ blue laser excitation, and the white lighting device fabricated by coupling commercial green-emitting LuAG: $\mathrm{Ce}^{3+}$ ceramic (purchased from Suzhou Chuangside New Material Co. ltd) and the $\mathrm{Mg}_{2} \mathrm{Al}_{4} \mathrm{Si}_{5} \mathrm{O}_{18}: \mathrm{Eu}^{2+}$ composite under the high-power $445 \mathrm{~nm}$ blue laser excitation were measured using an integrating sphere of $1.0 \mathrm{~m}$ in diameter connected to a CCD detector.

\section{Computational methodology}

Periodic density functional theory (DFT) calculations on $\mathrm{Mg}_{2} \mathrm{Al}_{4} \mathrm{Si}_{5} \mathrm{O}_{18}: \mathrm{Eu}^{2+}$ were conducted using the PerdewBurke-Ernzerhof $(\mathrm{PBE})^{45}$ functional and its $\mathrm{PBE}+\mathrm{U}$ variant with $U_{\text {eff }}=2.5 \mathrm{eV}$ for the $\mathrm{Eu} 4 f$ electrons $^{46,47}$, as 
implemented in the Vienna $\mathrm{Ab}$ initio Simulation Package (VASP) $c o d e^{48,49} \cdot \operatorname{Mg}\left(2 \mathrm{p}^{6} 3 \mathrm{~s}^{2}\right), \quad \mathrm{Al}\left(3 \mathrm{~s}^{2} 3 \mathrm{p}^{1}\right), \quad \mathrm{Si}\left(3 \mathrm{~s}^{2} 3 \mathrm{p}^{6}\right), \quad \mathrm{O}$ $\left(2 s^{2} 2 p^{4}\right)$, and $\mathrm{Eu}\left(5 \mathrm{~s}^{2} 5 \mathrm{p}^{6} 4 \mathrm{f}^{7} 6 \mathrm{~s}^{2}\right)$ were treated as valence electrons, and their interactions with the respective cores were described by the projected augmented wave approach ${ }^{50}$. The investigation of $\mathrm{Eu}^{2+}$-doping in $\mathrm{Mg}_{2} \mathrm{Al}_{4} \mathrm{Si}_{5} \mathrm{O}_{18}$ was modeled by incorporating a $\mathrm{Eu}$ in the unit cell (58 atoms), with appropriate charge compensators as described in the text. The atomic structures of undoped and doped supercells were fully optimized until the total energies and the forces on the atoms converged to $10^{-6} \mathrm{eV}$ and $0.01 \mathrm{eV}^{-1}$. A $2 \times 2 \times 2 \mathrm{k}$ point grid was used, and the cutoff energy for the plane wave basis was set to $530 \mathrm{eV}$. The formation energies of $\mathrm{Eu}^{2+}$ related isolated defects or defect complexes were calculated using $\Delta E_{\mathrm{f}}=E$ (doped) $-E$ (undoped) $+\sum \Delta n_{\mathrm{A}} \mu_{\mathrm{A}}$, where $E$ (doped) and $E$ (undoped) denote DFT total energies of the doped and undoped unit cells, respectively. $\Delta n_{\mathrm{A}}$ is the number of species $A$ ( $=\mathrm{Eu}, \mathrm{Mg}, \mathrm{Al}$, or $\mathrm{Si}$ ) removed from the undoped cell to introduce point defects, and $\mu_{\mathrm{A}}$ is the corresponding atomic chemical potential, which was approximated by the energy of the corresponding metallic atom in view of the fact that the material was prepared in the reducing atmosphere.

\section{Acknowledgements}

The present work was supported by the National Natural Science Foundations of China (Grant Nos. 51972118, 51961145101, 51722202 and 11974022), the Guangzhou Science \& Technology Project (202007020005), the Fundamental Research Funds for the Central Universities (D2190980), and the Local Innovative and Research Teams Project of Guangdong Pearl River Talents Program (2017BT01X137).

\section{Author details \\ ${ }^{1}$ School of Physics and Optoelectronics, State Key Laboratory of Luminescent Materials and Devices and Guangdong Provincial Key Laboratory of Fiber Laser Materials and Applied Techniques, South China University of Technology, Guangzhou, Guangdong, China. ${ }^{2}$ Anhui Key Laboratory of Optoelectric Materials Science and Technology, Key Laboratory of Functional Molecular Solids, Ministry of Education, Anhui Normal University, Wuhu, Anhui, China. ${ }^{3}$ School of Applied Physic and Materials, Wuyi University, Jiangmen, Guangdong, China. ${ }^{4}$ Ministry of Education Key Laboratory of Bioinorganic and Synthetic Chemistry, State Key Laboratory of Optoelectronic Materials and Technologies, KLGHEl of Environment and Energy Chemistry, School of Chemistry and Chemical Engineering, Sun Yat-sen University, Guangzhou, Guangdong, China. ${ }^{5}$ Laboratory of Crystal Physics, Kirensky Institute of Physics, Federal Research Center KSC SB RAS, Krasnoyarsk, Russia. ${ }^{6}$ Siberian Federal University, Krasnoyarsk, Russia. ${ }^{7}$ Research and Development Department, Kemerovo State University, Kemerovo, Russia. ${ }^{8}$ Institute of Microstructure and Property of Advanced Materials, Beijing University of Technology Beijing, Beijing, China \\ Author contributions \\ H.Z., G.X., and Q.Y.Z. conceived the project, wrote the paper and were primarily responsible for the experiment. L.X.N performed the DFT calculations and was responsible for discussion of the results. G.Y. carried out photoluminescence measurements. J.W.Q., E.H.S., and Z.T.C. were responsible for discussion of the results. J.W. and Y.Y.Z. helped to fabricate LD devices. M.M. performed the structure refinement. X.X.K. performed the STEM measurement. All authors contributed to the general discussion.}

\section{Conflict of interest}

The authors declare no competing interests.
Supplementary information The online version contains supplementary material available at https://doi.org/10.1038/s41377-021-00498-6.

Received: 17 January 2021 Revised: 9 February 2021 Accepted: 24 February 2021

Published online: 12 March 2021

\section{References}

1. Pust, P., Schmidt, P. J. \& Schnick, W. A revolution in lighting. Nat. Mater. $\mathbf{1 4}$ 454-458 (2015)

2. Pimputkar, S. et al. Prospects for LED lighting. Nat. Photonics 3, 180-182 (2009).

3. Schubert, E. F. \& Kim, J. K. Solid-state light sources getting smart. Science $\mathbf{3 0 8}$, 1274-1278 (2005)

4. Xia, Z. G. \& Liu, Q. L. Progress in discovery and structural design of color conversion phosphors for LEDs. Prog. Mater. Sci. 84, 59-117 (2016).

5. Kim, Y. H. et al. A zero-thermal-quenching phosphor. Nat. Mater. 16, 543-550 (2017).

6. Pust, P. et al. Narrow-band red-emitting $\mathrm{Sr}\left[\mathrm{LiAl}_{3} \mathrm{~N}_{4}\right]$ : $\mathrm{Eu}^{2+}$ as a next-generation LED-phosphor material. Nat. Mater. 13, 891-896 (2014).

7. Zhao, M. et al. Next-generation narrow-band green-emitting $\mathrm{RbLi}\left(\mathrm{L}_{3} \mathrm{SiO}_{4}\right)_{2}$ : $\mathrm{Eu}^{2+}$ phosphor for backlight display application. Adv. Mater. 30, 1802489 (2018).

8. Wierer, J. J. Jr, Tsao, J. Y. \& Sizov, D. S. Comparison between blue lasers and light-emitting diodes for future solid-state lighting. Laser Photonics Rev. 7, 963-993 (2013)

9. Cho, J., Schubert, E. F. \& Kim, J. K. Efficiency droop in light-emitting diodes: challenges and countermeasures. Laser Photonics Rev. 7, 408-421 (2013).

10. Lenef, A. et al. Phosphor performance under high intensity excitation by InGaN laser diodes. ECS J. Solid State Sci. Technol. 9, 016019 (2019).

11. Li, S. X. et al. Color conversion materials for high-brightness laser-driven solidstate lighting. Laser Photonics Rev. 12, 1800173 (2018).

12. Huang, J. L. et al. Rapid degradation of mid-power white-light LEDs in saturated moisture conditions. IEEE Trans. Device Mater. Reliab. 15, 478-485 (2015).

13. Lin, H. et al. Glass ceramic phosphors: towards long-lifetime high-power white light-emitting-diode applications-a review. Laser Photonics Rev. 12, 1700344 (2018).

14. Arjoca, S. et al. Temperature dependence of Ce:YAG single-crystal phosphors for high-brightness white LEDs/LDs. Mater. Res. Express 2, 055503 (2015).

15. Yao, Q. et al. YAG:Ce ${ }^{3+}$ transparent ceramic phosphors brighten the nextgeneration laser-driven lighting. Adv. Mater. 32, 1907888 (2020).

16. Zhang, R. et al. A new-generation color converter for high-power white LED: transparent $\mathrm{Ce}^{3+}$ :YAG phosphor-in-glass. Laser Photonics Rev. 8, 158-164 (2014).

17. Zhang, D. et al. Highly efficient phosphor-glass composites by pressureless sintering. Nat. Commun. 11, 2805 (2020).

18. Huang, P. et al. Nano wave plates structuring and index matching in transparent hydroxyapatite-YAG: Ce composite ceramics for high luminous efficiency white light-emitting diodes. Adv. Mater. 32, 1905951 (2020).

19. Hoerder, G. J. et al. $\mathrm{Sr}\left[\mathrm{Li}_{2} \mathrm{Al}_{2} \mathrm{O}_{2} \mathrm{~N}_{2}\right]: \mathrm{Eu}^{2+}{ }_{-} \mathrm{A}$ high performance red phosphor to brighten the future. Nat. Commun. 10, 1824 (2019).

20. Qiao, J. W. et al. Site-selective occupancy of $\mathrm{Eu}^{2+}$ toward blue-light-excited red emission in a $\mathrm{Rb}_{3} \mathrm{YSi}_{2} \mathrm{O}_{7}$ :Eu phosphor. Angew. Chem. Int. Ed. 58, 11521-11526 (2019).

21. Wang, R. et al. Red-emitting improvement of $\mathrm{CaAlSiN}_{3}: \mathrm{Eu}^{2+}$ phosphor-in-glass: insight into the effect of atmospheric pressure preparation on photoluminescence properties and thermal degradation. J. Lumin. 225, 117390 (2020).

22. Li, S. X. et al. New insights into the microstructure of translucent $\mathrm{CaAlSiN}_{3}: \mathrm{Eu}^{2+}$ phosphor ceramics for solid-state laser lighting. J. Mater. Chem. C 4, 1042-1051 (2017).

23. Allix, M. et al. Highly transparent $\mathrm{BaAl}_{4} \mathrm{O}_{7}$ polycrystalline ceramic obtained by full crystallization from glass. Adv. Mater. 24, 5570-5575 (2012).

24. Alahraché, $\mathrm{S}$. et al. Crystallization of $\mathrm{Y}_{2} \mathrm{O}_{3}-\mathrm{Al}_{2} \mathrm{O}_{3}$ rich glasses: synthesis of $\mathrm{YAG}$ glass-ceramics. J. Phys. Chem. C. 115, 20499-20506 (2011).

25. $\mathrm{Ma}, \mathrm{X}$. G. et al. Pressureless glass crystallization of transparent yttrium aluminum garnet-based nanoceramics. Nat. Commun. 9, 1175 (2018).

26. Zhou, S. F. et al. Simultaneous tailoring of phase evolution and dopant distribution in the glassy phase for controllable luminescence. J. Am. Chem. Soc. 132, 17945-17952 (2010). 
27. Chen, D. Q. et al. Simultaneous tailoring of dual-phase fluoride precipitation and dopant distribution in glass to control upconverting luminescence. ACS Appl. Mater. Interfaces 11, 30053-30064 (2019).

28. Chowdhury, A. et al. Synthesis, properties and applications of cordierite ceramics, Part 1. Int. Ceram. Rev. 56, 18-22 (2007).

29. Chen, J. et al. The luminescence properties of novel $\mathrm{a}-\mathrm{Mg}_{2} \mathrm{Al}_{4} \mathrm{Si}_{5} \mathrm{O}_{18}: \mathrm{Eu}^{2+}$ phosphor prepared in air. RSC Adv. 4, 18234-18239 (2014).

30. Zhou, J. et al. New insight into phase formation of $\mathrm{M}_{x} \mathrm{Mg}_{2} \mathrm{Al}_{4+x} \mathrm{Si}_{5-x} \mathrm{O}_{18}: \mathrm{Eu}^{2+}$ solid solution phosphors and its luminescence properties. Sci. Rep. 5, 12149 (2015).

31. Song, $\mathrm{K}$. et al. Synthesis and luminescence characteristics of $\mathrm{Mg}_{2} \mathrm{Al}_{4} \mathrm{Si}_{5} \mathrm{O}_{18}: \mathrm{Eu}^{2+}$ and nitrided $\mathrm{Mg}_{2} \mathrm{Al}_{4} \mathrm{Si}_{5} \mathrm{O}_{18}: \mathrm{Eu}^{2+}$ phosphors. J. Lumin. 224, 117317 (2020).

32. Stefańska, D. \& Dereń, P. J. High efficiency emission of Eu ${ }^{2+}$ located in channel and $\mathrm{Mg}$-site of $\mathrm{Mg}_{2} \mathrm{Al}_{4} \mathrm{Si}_{5} \mathrm{O}_{18}$ cordierite and its potential as a Bi-functional phosphor toward optical thermometer and white LED application. Adv. Optical Mater. 8, 2001143 (2020).

33. Komatsu, T. Design and control of crystallization in oxide glasses. J. Non-Cryst. Solids 428, 156-175 (2015).

34. Höland, W. \& Beall, G. H. Glass-Ceramic Technology 2nd edn (Wiley, 2012).

35. Bruker, A. X. S. TOPAS, V4: General Profile and Structure Analysis Software for Powder Diffraction Data-User's Manual (Bruker AXS, 2008).

36. Clayden, N. J. et al. Solid state ${ }^{27} \mathrm{Al}$ NMR and FTIR study of lanthanum aluminosilicate glasses. J. Non-Cryst. Solids 258, 11-19 (1999).

37. Mozgawa, W. \& Sitarz, M. Vibrational spectra of aluminosilicate ring structures. J. Mol. Struct. 614, 273-279 (2002).

38. Hume-Rothery, W. \& Powell, H. M. On the theory of super-lattice structures in alloys. Z. f.ür. Kristallographie 91, 23-47 (1935).
39. Thomas, P. et al. Powder neutron diffraction study of alkali-substituted cordierites with $\mathrm{M}_{x} \mathrm{Mg}_{2} \mathrm{Al}_{4+x} \mathrm{Si}_{5-x} \mathrm{O}_{18}(\mathrm{M}=\mathrm{K}, \mathrm{Cs} ; 0<\mathrm{x} \leq 1)$ formula. Eur. J. Solid State Inorg. Chem. 28, 1011-1120 (1991).

40. Grau-Crespo, R. et al. Symmetry-adapted configurational modelling of fractional site occupancy in solids. J. Phys. Condens. Matter 19, 256201 (2007).

41. Poort, S. H. M., Meyerink, A. \& Blasse, G. Lifetime measurements in Eu²+doped host lattices. J. Phys. Chem. Solids 58, 1451-1456 (1997).

42. Dorenbos, $\mathrm{P}$. Thermal quenching of $\mathrm{Eu}^{2+} 5 \mathrm{~d}-4 \mathrm{f}$ luminescence in inorganic compounds. J. Phys. Condens. Matter 17, 8103 (2005).

43. Qiao, J. W. et al. Eu ${ }^{2+}$ site preferences in the mixed cation $\mathrm{K}_{2} \mathrm{BaCa}\left(\mathrm{PO}_{4}\right)_{2}$ and thermally stable luminescence. J. Am. Chem. Soc. 140, 9730-9736 (2018).

44. Dorenbos, P. Anomalous luminescence of $\mathrm{Eu}^{2+}$ and $\mathrm{Yb}^{2+}$ in inorganic compounds. J. Phys. Condens. Matter 15, 2645 (2003).

45. Perdew, J. P., Burke, K. \& Ernzerhof, M. Generalized gradient approximation made simple. Phys. Rev. Lett. 77, 3865-3868 (1996).

46. Canning, A. et al. First-principles study of luminescence in Ce-doped inorganic scintillators. Phys. Rev. B 83, 125115 (2011).

47. Dudarev, S. L. et al. Electron-energy-loss spectra and the structural stability of nickel oxide: an LSDA + U study. Phys. Rev. B 57, 1505-1509 (1998).

48. Kresse, G. \& Furthmüller, J. Efficient iterative schemes for ab initio totalenergy calculations using a plane-wave basis set. Phys. Rev. B 54, 11169-11186 (1996).

49. Kresse, G. \& Joubert, D. From ultrasoft pseudopotentials to the projector augmented-wave method. Phys. Rev. B 59, 1758-1775 (1999).

50. Blöchl, P. E. Projector augmented-wave method. Phys. Rev. B 50, 17953-17979 (1994). 